\title{
Sintering Kinetics of Soft-Doped PZT (54/46) Systems
}

\author{
M. D. Durruthy-Rodríguez ${ }^{1,2}$, F. Calderón-Piñar ${ }^{3}$, C. Malfatti ${ }^{4}$, L. D. Pérez-Fernández ${ }^{5}$ \\ ${ }^{1}$ Applied Physics Department, Cybernetic, Mathematic and Physics Institute, Vedado, \\ Havana City, Havana, Cuba \\ ${ }^{2}$ CINVESTAV-Unidad Querétaro, IPN, Libramiento Norponiente No. 2000, Fracc. \\ Real de Juriquilla, Querétaro, Querétaro, México \\ ${ }^{3}$ Magnetism Laboratory, Science and Materials Technology Institutes, Havana University, San Lázaro y L, \\ Vedado, Havana City, Cuba \\ ${ }^{4}$ Metalurgy Deparment, Engeneering School, Rio Grande do Sul Federal University, Porto Alegre, RS - Brasil \\ ${ }^{5}$ Applied Physics Department, Cybernetic, Mathematic and Physics Institute Vedado, \\ Havana City, Havana, Cuba \\ E-mail:dolores@icmf.inf.cu, leslie@icmf.inf.cu,calderon@fisica.uh.cu,malfattimc@gmail.com, leslie@icmf.inf.cu \\ Received February 9, 2011; revised April 13, 2011; accepted April 16, 2011
}

\begin{abstract}
The influence of dopant concentration on PZT (54/46) systems doped with lanthanum and/or niobium is studied. The sintering kinetics is presented for $1 \mathrm{wt} \%$ of the dopant used to find the main mechanism which drives this process. The results were compared with a phenomenological model for viscous sintering and solid state sintering. The exponent obtained for viscous sintering in PZTN, PLZT and PLZTN were 0.05, 0.01 , and 0.23 respectively, which indicate that the process is reactive liquid in all cases. In the other hand, the exponent obtained for solid state sintering were 6.61, 5.68, and 1.23 respectively, and prevalence Ostwald ripening and coalescence process together. Both dopants inhibit the grain growth and accelerate the sintering process, which increases with dopant concentration and the combination of both dopants. Shorohod-Olevsky model was applied for explain grain growth evolution, but does not coincide strictly with the applied model, which suggests that the process is very complex.
\end{abstract}

Keywords: Sintering Kinetics, Porosity, Dopant Concentration

\section{Introduction}

Because doped PZT (54/46) piezoceramics are polycrystalline, their microstructural characteristics (grain size and orientation distribution, phase distribution, phase and domain morphology) as well as their defects (atomic structures of domain walls, native defects, impurities) play crucial roles in determining their properties [1]. Usually, some of these factors act simultaneously, making the polarization switching phenomena very intricate. The local densification effect [2] is one of the most important technological problems related to sintering, as a strong densification may occur in some parts of a porous body while large pores appear in others. This shows the instability caused by initially-small heterogeneities in the spatial distribution of pores, and may lead to various microstructural defects nucleation producing macroscopic lattice and damage. A non-uniform density distribution provoked by sintering instability may cause poor mechanical properties of the final product. Sintering is generally incapable of compensating defects introduced in earlier processing steps. Understanding the influence of such defects is a fundamental challenge.

Some of the possible reactions when obtaining the perovskite $\mathrm{ABO}_{3}$ are: replacing $\mathrm{Pb}^{2+}$ by $\mathrm{La}^{3+}$ with vacancy $V$ compensating in site $A\left(\mathrm{~Pb}_{1-3 \times / 2} \mathrm{La}_{\mathrm{x}} \mathrm{V}_{\mathrm{x} / 2}\right.$ $\left.\left(\mathrm{Zr}_{0.54} \mathrm{Ti}_{0.46}\right) \mathrm{O}_{3}\right)$ or $\mathrm{B}\left(\mathrm{Pb}_{1-3 \times / 2} \mathrm{La}_{\mathrm{x}} \mathrm{V}_{\mathrm{x} / 2}\left(\mathrm{Zr}_{0.54} \mathrm{Ti}_{0.46}\right)_{1-\mathrm{x} / 4} \mathrm{~V}_{\mathrm{x} / 4} \mathrm{O}_{3}\right)$, and replacing $\mathrm{Ti}^{4+}\left(\mathrm{Zr}^{4+}\right)$ by $\mathrm{Nb}^{5+}$ compensating in $A$ $\left(\mathrm{Pb}\left(\mathrm{Zr}_{0.54} \mathrm{Ti}_{0.46}\right)_{1-5 \mathrm{y} / 4} \mathrm{~N}_{\mathrm{y}} \mathrm{V}_{\mathrm{y} / 4} \mathrm{O}_{3}\right)$ or

$\mathrm{B}\left(\mathrm{Pb}_{1-\mathrm{y} / 2} \mathrm{~V}_{\mathrm{y} / 2}\left(\mathrm{Zr}_{0.54} \mathrm{Ti}_{0.46}\right)_{1-\mathrm{y}} \mathrm{Nb}_{\mathrm{y}} \mathrm{O}_{3}\right)$. The positions with increasing vacancies will generate pores. Here, the influence of dopant concentration on the densification process during sintering is studied.

\section{Experiment}

The samples were prepared for $\mathrm{Pb}\left(\mathrm{Zr}_{0.54} \mathrm{Ti}_{0.46}\right) \mathrm{O}_{3}+x$ wt\% $\mathrm{D}$, where dopant $\mathrm{D}$ is $\mathrm{Nb}_{2} \mathrm{O}_{5}(\mathrm{PZTN})$ or $\mathrm{La}_{2} \mathrm{O}_{3}$ (PLZT), 
and $x=0.02,0.04,0.06,0.08,0.10$; and $\mathrm{Pb}_{1-3 \mathrm{x} / 2} \mathrm{La}_{x} \mathrm{~V}_{x / 2}^{\mathrm{Pb}}$ $\left(\mathrm{Zr}_{0.54} \mathrm{Ti}_{0.46}\right)_{1-5 \mathrm{y} / 4} \mathrm{~N}_{y} \mathrm{~V}_{y / 4}^{\mathrm{ZrTi}} \mathrm{O}_{3}$ (PLZTN) for simultaneous doping with $x=y=0.04,0.08,0.1$. Reagent purities are: $\mathrm{PbCO}_{3}$ 98\%, BDH; $\mathrm{ZrO}_{2}$ 99\%, Merck; $\mathrm{TiO}_{2}$ 99\%, Riedel of Haën; $\mathrm{Nb}_{2} \mathrm{O}_{5}$ spectrally pure, JMC; and $\mathrm{La}_{2} \mathrm{O}_{3}$ spectrally pure, Merck. The components were mixed via humid milling with ethylic alcohol in an agate mortar mill during $90 \mathrm{~min}$, and the calcinations were made at $960^{\circ} \mathrm{C}$ during $90 \mathrm{~min}$ in a covered alumina crucible. The samples were sintered in lead atmosphere at $1200^{\circ} \mathrm{C}$ and $1250^{\circ} \mathrm{C}$ during different times.

\section{Results and Discussion}

\subsection{Characterization of the Sintering Process}

Mainly, two approaches are used to explain the sintering process: the mesoscopic microstructural model, and the continuum phenomenological model. Here, we use Olevsky's model [3], which corresponds to the second approach and is based on the plasticity and the viscous theory of linear deformation of porous bodies [2,4,5]. In this work, the relative density $\rho_{\text {rel }}$, the sintering rate $\varepsilon_{\rho}^{*}$, and the volumetric shrinkage $\Theta$ are used as control parameters[6].

The isothermal rate of grain growth can be expressed by phenomenological kinetics grain growth equation $[7,8]$ :

$$
G^{n}-G_{0}^{n}=K_{0} t \exp (-Q / R T)
$$

where $G$ is the average size at time $t, G_{0}$ is the initial grain size, $\mathrm{n}$ is the kinetic grain growth exponent value, $K_{0}$ is a constant, $Q$ is apparent activation energy, $R$ is the gas content, and $\mathrm{T}$ is the absolute temperature. Whenever $G_{0}$ is significantly smaller than $G$, then $G_{0}$ can be neglected and Equation 1 simplifies to

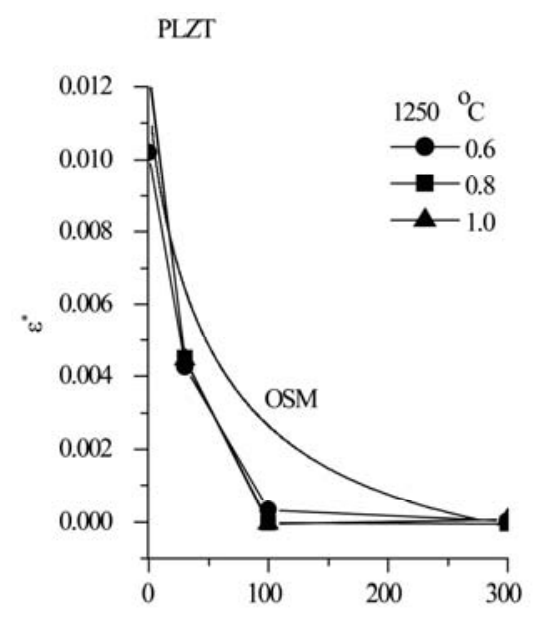

PZIN

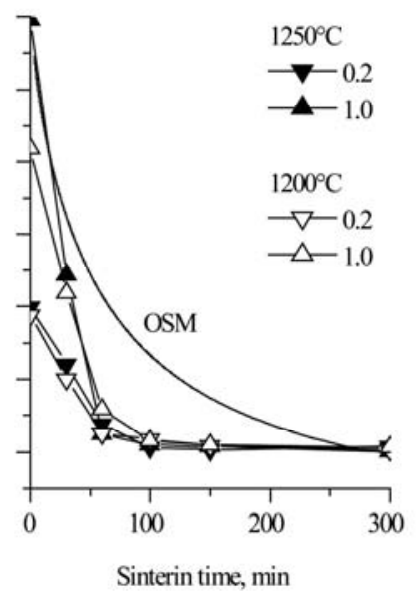

$$
G^{n}=K_{0} t \exp (-Q / R T)
$$

and this equation can be transformed into

$$
\ln G=(1 / n) \ln t+(1 / n) \ln K_{0} \exp (-Q / R T)
$$

The $n$ value can be calculated from slope of $\ln G$ versus $\ln t$ line plot, the grain growth kinetic exponent is readily determined.

Initial and final densities were obtained from the dimensions and mass of the samples by measuring with a micrometer $( \pm 0.01 \mathrm{~mm})$ and a Sartorius balance $\left( \pm 10^{-4}\right.$ g). SEM was applied with a JSM-5800 microscope (MAG, ×1000; ×2000; ×3500; ×10 000; ACCV $10 \mathrm{kV}$ and $15 \mathrm{kV}$ ) to describe the samples microstructures and characteristics.

\subsection{Densification Process}

PLZT and PZTN samples attained sintering state at 60 and 100 min respectively with $\rho_{\text {rel }} \simeq 90 \%-95 \% \rho_{T}$, with $\rho_{T}$ as the theoretical density, and exhibited similar behaviors for $x>0.6$. For PZTN and PLZTN samples with low niobium concentrations, $\rho_{\text {rel }}$ dependence is observed. In all cases, the loss of mass is smaller than $2 \%$. Both, $\varepsilon_{\rho}^{*}$ and $\Theta$ ratify $\rho_{\text {rel }}$ behavior. $\rho_{\text {rel }}$ and $\varepsilon_{\rho}^{*}$ confirm typical ceramic behavior with viscous sintering [1-3]. Independent substitutions in $A$ and $B$ have equal influence in the sintering parameters for equal dopant concentrations $(x=0.06,0.08,0.10)$. This substitution type causes a decreasing $\varepsilon_{\rho}^{*}$ and increasing $\rho_{\text {rel }}$ and $\Theta$. A strong dependence of the sintering parameters on dopant concentration is evident. The experimental results for the three compositions do not adjust strictly to the Skorohod-Olevsky Model (SOM)[9] for $\varepsilon_{\rho}^{*}$ (Figure 1), the best results were for PLZT and PLZTN samples,

\section{PLZIN}

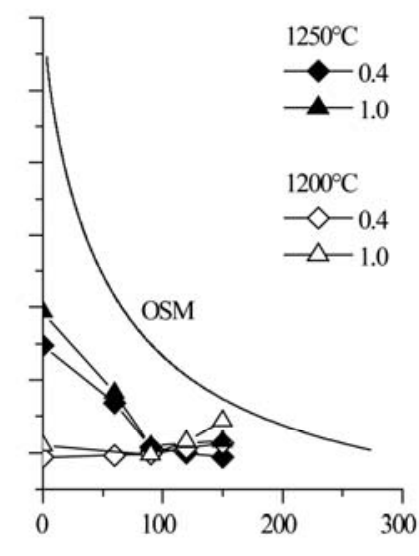

Figure 1. Experimental and the SOM results for the sintering rate $\varepsilon_{\rho}^{*}$. None of the three cases coincides with the model, only PZTN follows the values of the model for the initial and final instants. 
as work compositions do not exhibit a unique grain size and the grains are not spherical. The density reached by all PLZTN samples is low. The importance of achieving sintering in the smallest possible time avoiding the lead loss is recognized [10]. In general, the best results correspond to $x=0.06,0.08,0.10$ and times of $60-100 \mathrm{~min}$. The mechanisms that govern the densification process are the decreasing superficial area and free energy via the elimination of the interface solid-vapor, and the fact that in the sintering process the interaction of grain and porosity is in both directions [12-14]. Samples porosity $\rho_{0}=1-\rho_{\text {rel }}$ [14] show the influence of the dopant $\mathrm{Nb}$ and $\mathrm{La}+\mathrm{Nb}$ concentrations for which the $p_{0}$ decreases (Figure 2(a)). For PZTN samples, $p_{0}$ varies from 23\% $10 \%$ in the initial states, to $17 \%-3 \%$ at the end of the process. For PLZTN samples, the variation is smaller
(12\% at the beginning and $10 \%$ at the end). As expected, $p_{0}$ also decreases with the sintering time, mainly for PZTN, due to the viscous sintering process, from 31\% $34 \%$ to $3 \%$ - 10\% (Figure 2(b)). For the PLZT, the variation of $p_{0}$ does not exhibit a defined tendency neither with La concentration nor sintering time. But the porosity have strong depends on the grain size, having a biggest growth for the PLZT samples (Figure 2(c)).

\subsection{SEM Analysis}

The grain sizes obtained of the microphotographs SEM of each one of the samples carrying out a statistical analysis of the measurement obtained, Figure 3 show the grain size evolution with dopant concentration for PLZT, PZTN and PLZTN.

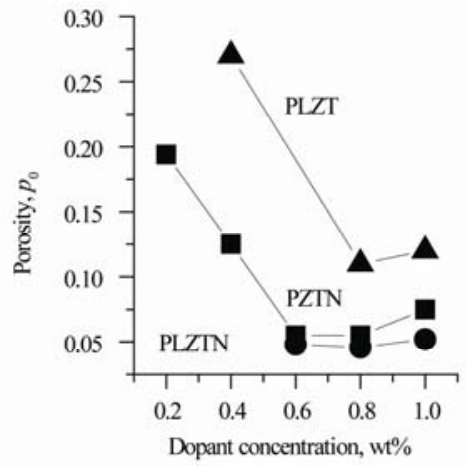

(a)

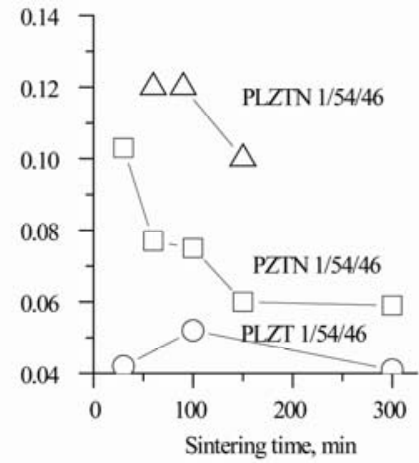

(b)

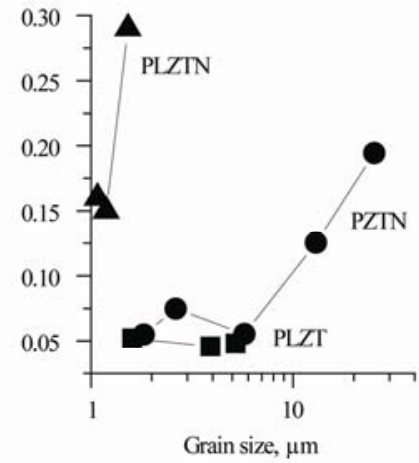

(c)

Figure 2. Behavior of the porosity $p_{0}$ with the dopant concentration, sintering time and the grain size of PLZT, PZTN and PLZTN ceramic samples sintered at $1250^{\circ} \mathrm{C}$. The porosity increased with the grain size in all cases.
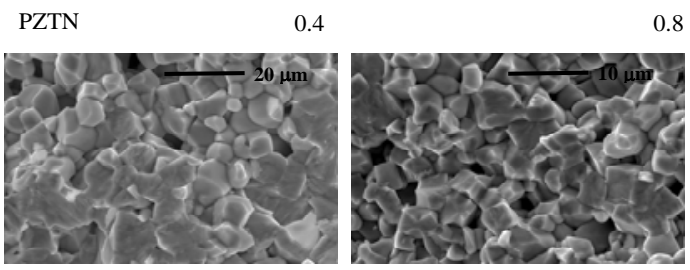

$\begin{array}{ll}0.8 & 1.0\end{array}$
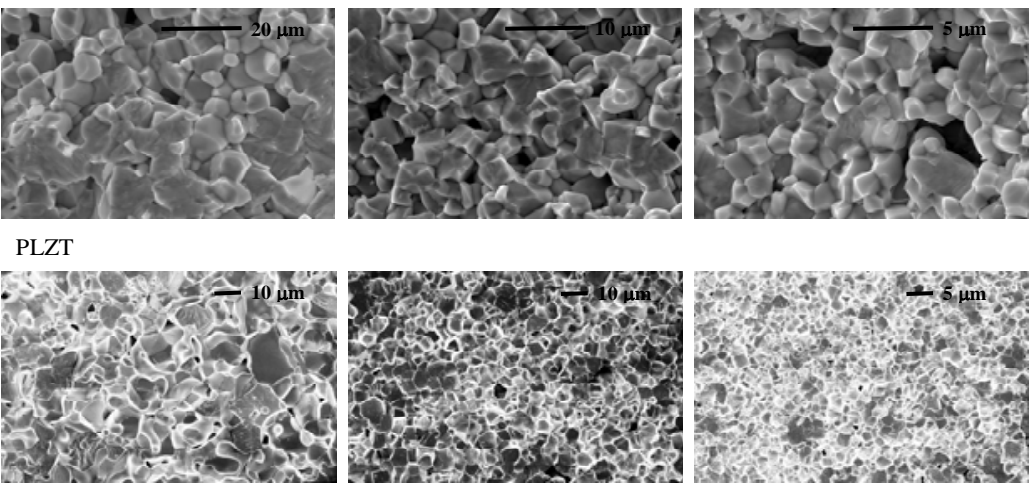

PLZTN
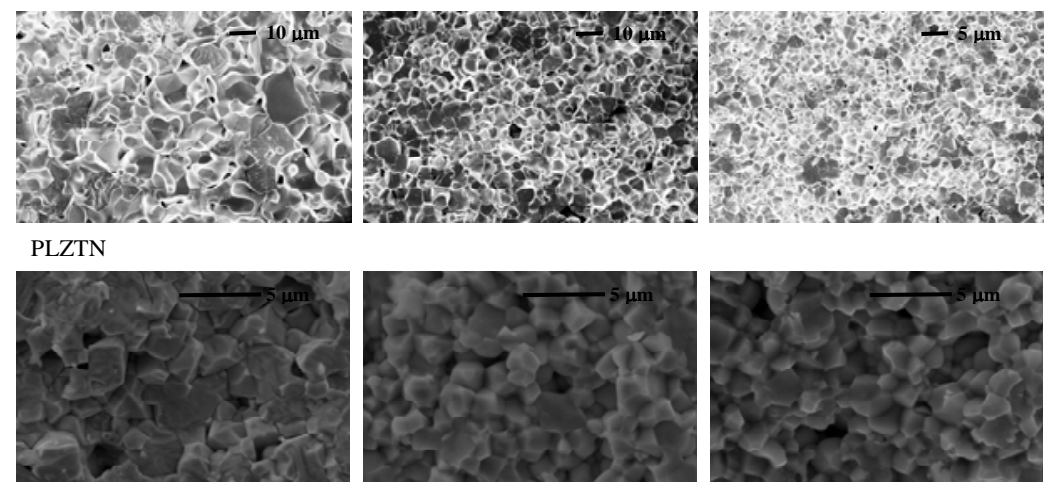

Figure 3. Behavior of grain size with dopant concentration. Only appear 0.4, 0.8 and 1.0 wt \% of PLZTN and PZTN, and 0.6, 0.8 and 1.0 wt \% for PLZT ceramics sintering at $1250^{\circ} \mathrm{C}$ during 100 minutes. 
Increasing dopant concentration implies that grain size decreases with narrower distribution (Table 1). The largest decrement is obtained for PLZTN with 0.8 and $1.0 \mathrm{wt} \%$. The double substitution shows a notable inhibiting effect of grain growth. It is evident that inhibiting the grain growth is the fundamental cause of the low $\rho_{\text {rel }}$ obtained by PLZTN samples. Moreover, it is not possible to eliminate the porosity as in the other compositions. The SEM analysis reveals the existence of a strong dependence between the dopant concentration, the grain size and its distribution (Figure 2(c)), independently of the sintering time. The sintering kinetics of the dopant used for $1 \mathrm{wt} \%$ allows determining the mechanism that prevails in the process. The results are compared with the phenomenological model proposed by Kingery[1] for viscous sintering, which provides a relationship between volumetric shrinkage and time via $\Theta=K t^{n}$, where $K$ is a parameter involving the viscosity, the superficial tension and the radius of the particles, and $n=2 / 5,2 / 3,1 / 3,1$ stand for processes with diffusion in the grain boundary, evaporation-condensation, a reactive liquid, and vitrification, respectively. The exponents obtained for PZTN, PLZT and PLZTN were 0.05, 0.01 and 0.23 , respectively, which indicates that a reactive liquid process occurs in the three cases (Figure 4). $\mathrm{La}^{3+}$ and $\mathrm{Nb}^{5+}$ dopants inhibit the grain growth strongly, so the behavior of the $\varepsilon_{\rho}^{*}$ and grain growth of the obtained materials does not coincide strictly with the applied sintering model, as the actual grains are not spherical and the density reached by some samples is low.

On the other hand, the average grain size increases with sintering temperatures as well as for longer sintering

Table 1. Dependence of the grain size on the sintering materials at $1250^{\circ} \mathrm{C}$ with dopant concentration.

\begin{tabular}{|c|c|c|c|}
\hline Dopant & wt \% & $\begin{array}{l}\text { Grain size interval } \\
\qquad(\mu \mathrm{m})\end{array}$ & $\begin{array}{c}\text { Average } \\
\text { grain size } \\
(\mu \mathrm{m})\end{array}$ \\
\hline \multirow{3}{*}{$\mathrm{La}$} & 0.6 & $1-9$ & $3 \pm 0.05$ \\
\hline & 0.8 & $1-7$ & $2 \pm 0.05$ \\
\hline & 1.0 & $1-2$ & $1 \pm 0.05$ \\
\hline \multirow{5}{*}{$\mathrm{Nb}$} & 0.2 & $14-36$ & $25 \pm 0.05$ \\
\hline & 0.4 & $6-20$ & $13 \pm 0.05$ \\
\hline & 0.6 & $2-10$ & $6 \pm 0.05$ \\
\hline & 0.8 & $1-5$ & $2 \pm 0.04$ \\
\hline & 1.0 & $1-6$ & $3 \pm 0.05$ \\
\hline \multirow{3}{*}{$\mathrm{La}+\mathrm{Nb}$} & $0.4-0.4$ & $1-4$ & $2 \pm 0.2$ \\
\hline & $0.8-0.8$ & $0.25-4$ & $1 \pm 0.2$ \\
\hline & $1.0-1.0$ & $1-3$ & $1 \pm 0.2$ \\
\hline
\end{tabular}

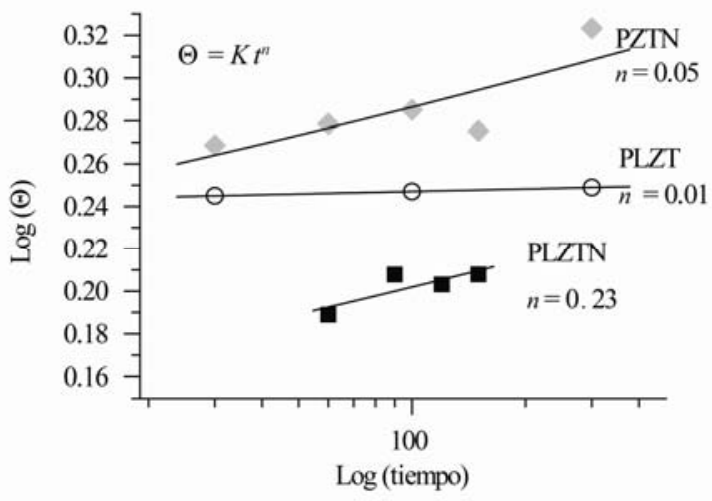

Figure 4. Analysis of the volumetric shrinkage $\Theta$ with the sintering time for PLZT, PZTN and PLZTN at 1.0/54/46.

times $[3,10]$. Figure 5 illustrates the isothermal grain growth results for PLZT 54/46, PZTN 54/46 and PLZTN $54 / 46$ sintered at $1250^{\circ} \mathrm{C}$. The results For PLZT are 0.5, 1.66, 3 and 5 hours; for PZTN 0.5, 1, 1.66, 2.5 and 5 hours, and for PLZTN 1, 1.5, 2 and 2.5 hours. In the form of Equation 3, the exponents obtained (n) were 6.61, 5.68, and 1.23 for PLZT, PZTN and PLZTN, respectively.

Usually, the $n$ value for ceramics was 2, and the rate determining step of the growth process was the diffusion. And when the $n$ value was 3, the rate determining step of the growth process was the Ostwald ripening process or lattice diffusion from the grain boundary, but for grain boundary diffusion the $n$ value was 4 , and for the leaded process by diffusion cross dislocation the $n$ value was 5 . In some cases, the $n$ value is possibly found higher (5 $11)$, because there are grain growths by coalescence $[15,16]$.

In this study the $n$ values were 6.61 and 5.68 for PLZT and PZTN, suggesting that the rate determining steps were coalescence in both cases, and for PLZTN $n=1.23$

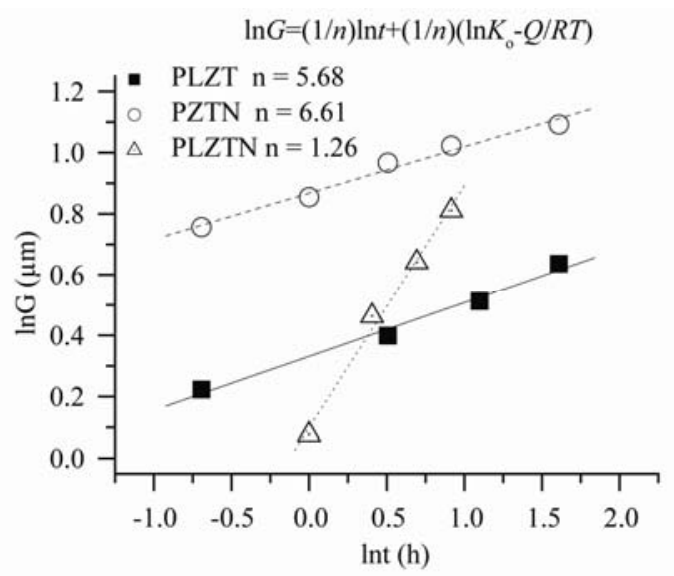

Figure 5. Grain growth of PLZT, PZTN and PLZTN at 1.0/54/46 ceramics. 
suggesting that the rate determining step was viscous flow.

The $n$ value was influenced by the particle size, the agglomeration shape and impurities type and content. The Consideration of all this results suggests that perhaps a grain growth mechanism occurs at critical impurities content and the mixing of dopants modified very much the sintering kinetics.

\section{Conclusions}

From the point of view of the sintering, the same dopant concentrations in $A$ and $B$, the results for $\rho_{\text {rel }}, \varepsilon_{\rho}^{*}$ and $\Theta$ are similar. For the combination $A+B$, the sintered state was not obtained. Both dopants inhibit the grain growth and accelerate the sintering process. This effect increases with the dopant concentration and with the combination of both dopants. The phenomenological model for viscous sintering suggests, in all the cases, that sintering is governed by a reactive liquid process. The phenomenological model for solid state sintering suggests for PLZT and PZTN that the sintering rate determining step was coalescence and for PLZTN the rate determining step was viscous flow. As the actual grains are not identical in size and shape, the theoretical results differs form the experimental ones to the SkorohodOlevsky Model.

\section{Acknowledgments}

The authors gratefully acknowledge the support from the project PNCB 10/04, Cuba, and Prof. Dr. Jose Antonio Eiras, Head of Department of Physics, Science and Technology Center, UFSCar, Brazil, for providing SEM facilities.

\section{References}

[1] W. D. Kingery, H. K. Bowen, D. R. Uhlmann, "Introduction to Ceramics,” John Wiley \& Sons, Inc., New York, 1976.

[2] M. Braginsky, V. Tikare, E. Olevsky, "Numerical Simulation of Solid State Sintering," International Journal of Solids Structures, Vol. 42, No. 2, 2005, pp. 621-636. doi:10.1016/j.ijsolstr.2004.06.022

[3] V. V. Skorohod, E. A. Olesvsky, M. B. Shtern, “Continnum Theory for Sintering of the Porous Bodies: Model and Application,” Science of Sintering, Vol. 23, No. 2, 1991, pp. 79-91.
[4] E. Olevsky, A. Molinari, "Instability of Sintering of Porous Bodies,” Internal Journal of Plasticity, Vol. 16, No. 1, 2000, pp. 1-37. doi:10.1016/S0749-6419(99)00032-7

[5] E. Olevsky, H. J. Dudek, W. A. Kaysser, "HIPing Conditions for Processing of Metal Matrix Composites Using the Continuum Theory for Sintering-I. Theoretical Analysis,” Acta Materialia, Vol. 44, No. 2, 1996, 707713. doi:10.1016/1359-6454(95)00179-4

[6] A. Boccaccini, D. M. R. Taplin, P. A. Trusty, C. B. Ponton, "Creep and Densification During Anisotropic Sintering of Glass Powders,” Journal of Material Science, Vol. 30, No. 22, 1995, pp. 5652-5656. doi:10.1007/BF00356700

[7] T. Senda, R. C. Bradt, "Grain Growth in Sintered ZnO and ZnO-Bi2O3 Ceramics," Journal of the American Ceramic Society, Vol. 73, No. 1, 1990, pp. 106-114. doi:10.1111/j.1151-2916.1990.tb05099.x

[8] Q. Shaojun, Chao Gao, Z. Xiaodong, G. Xiaoxian, Y. Chen, C. Jin, F. Pinyang, F. Huiqing, "Grain Growth in Sintered Porous $\mathrm{Pb}(\mathrm{Zr0.95Ti0.05)O3} \mathrm{Ceramics,”} \mathrm{Solid}$ State Ionics, Vol. 179, No. 21-26, 2008, pp. 875-877. doi:10.1016/j.ssi.2008.01.050

[9] V. V. Skorohod, "Rheological Basis of Theory of Sintering,” Naukova Durka, Kiev, 1972. doi:10.1111/j.1151-2916.1998.tb02768.x

[10] M. Hammer, M. J. Hoffmann, "Sintering Model for Mixed-Oxide-Derived Lead Zirconate Titanate Ceramics," Journal of the American Ceramic Society, Vol. 81, No. 12, 1998, pp. 3277-3284. doi: 10.1111/j.1151-2916.1998.tb02768.x

[11] J. J. Prieto, M. D. Durruthy, F. Calderón, A. Tuero, A. Silverio, Rev Cub Fis, VI, 71 (1986).

[12] J. J. Prieto, M. D. Durruthy, F. Calderón, J. C. Llópiz, Rev Cub Fis, VI, 77 (1986).

[13] M. D. Durruthy, J. J. Prieto, A. Victorero, Rev Lat Met Mat, 9, 18 (1989).

[14] W. Wersing, K. Lubitz, J. Mohaupt, "Dielectric, Elastic and Piezoelectric Properties of Porous Pzt Ceramics," Ferroelectrics, Vol. 68, No. 1, 1986, pp. 77-97. doi:10.1080/00150198608238739

[15] O. Bustos, R. Leiva, C. Sanchez, S. Ordoñez, L. Carvajal, R. Mannheim, "Evolución microestructural y propiedades reológicas de la aleación AA6063 fabricada mediante técnicas de procesado semisólido (SIMA y MHD)," Revista de Metalugia, Vol. 43, No. 3, 2007, pp. 165-180. doi:10.3989/revmetalm.2007.v43.i3.62

[16] Suk-Joong L. Kang, "Sintering: Densification, Grain Growth and Microstructure,” Elsevier, Butterworth Heinemann, 2005, ISBN 0-7506-6385-5. 